\title{
CT-Guided Percutaneous Fine Needle Aspiration Cytology of Pulmonary Mass.
}

\author{
Rajive Raj Shahi ${ }^{1}$, Mukunda Singh Shrestha ${ }^{1}$, Sujata Pant ${ }^{1}$, Sunil Singh ${ }^{2}$, Dinesh Maharjan ${ }^{1}$. \\ ${ }^{1}$ Department of Radiology, Shree Birendra Hospital, ${ }^{2}$ Department of Pathology, Shree Birendra Hospital.
}

\begin{abstract}
Introduction:Following the first study of Computed tomography guided trans thoracic biopsy of lung lesion by Haaga and Alfidi in 1976, CT guided transthoracic biopsy has been widely used for confirming the diagnosis of suspicious lung lesions. This study is aimed to assess the effectiveness of Transthoracic percutaneous fine needle aspiration cytology and frequency of associated complications.
\end{abstract}

Methods: A retrospective, hospital based study was performed between 11/06/2008 and 1/12/2009 atDepartment of Radiology, Shree Birendra Hospital, Kathmandu, Nepal.Thirty nine consecutive cases of lung lesions who underwent Trans Thoracic Percutaneous Fine Needle Aspiration Cytology (TTFNAC) under CT guidance were analysed. Smears of the aspirated material were evaluated by the pathology consultant (cytopathological evaluation) for adequacy

Results: There was adequate material for a cytopathological diagnosis in thirty four (87.18 \%) cases. Two cases were hemorrhagic while three cases revealed only reactive cells thus inadequate and non representative case constituted (12.8\%). Eight cases were reported as benign (23.53\%). Twenty three samples (67.65\%) were reported as definite malignant cases and three cases (8.82\%) showed atypical cells, suggestive of malignancy. Squamous cell carcinoma was the single most frequent histological diagnosis (12 cases).

Conclusions: The FNAC of lung is useful, safe and economical technique providing $87 \%$ diagnostic accuracy for lung mass without significant increase in complications.

Keywords: cytology, CT guided, fine needle aspiration cytology, lung mass.

\section{INTRODUCTION}

Both neoplastic (benign and malignant) and nonneoplastic lung parenchymal lesions are common pathological lung findings. There are many diagnostic tools and tests available including the simple sputum examination to broncheo-alveloar lavage and endoscopic bronchial biopsies. Ultrasound guided, fluroscopy guided, MRI guided and open lung biopsies remain the other invasive options available.
The first aspiration biopsy (puncture of lung) was performed by Leyden, for the diagnosis of pneumonia in $1883^{1}$. Dahlgren and Nordenstorm ${ }^{2}$ published a study concluding 87\% diagnostic accuracy in 1966 following which, trans-thoracic FNAC gained wider acceptance. Haaga and Alfidi reported the first Computed Tomography (CT)-guided lung biopsy in $1976^{3}$.

CT-guided percutaneous fine-needle aspiration cytology (FNAC) of suspicious lung lesions is a widely accepted diagnostic method with relatively low cost and negligible mortality and limited morbidity. FNAC is helpful in

\author{
Correspondence: \\ Lt. Col. Dr Rajive Raj Shahi \\ Department of Radiology, Shree Birendra Hospital \\ Kathmandu, Nepal \\ Email: rrshahi@hotmail.com \\ Phone: +977-9841909637
}


confirming the diagnosis (benign or malignant nature) which would help the clinicians in deciding the therapeutic management ${ }^{4}$.

Objective of this study was to determine the accuracy and complications of CT-guided FNAC at our center and evaluate the pathological spectrum of the lung nodules/masses. Chest pain at FNAC site, haemorrhage, haemoptysis and pneumothorax are some of the common complications associated with trans-thoracic FNAC of the lung nodule. The more serious complications include pericaridaltamponade, systemic air embolism and seeding of malignant cells in the needle tract.

\section{METHODS}

Case records of thirty nine patients with lung lesions on plain CXR and CECT chest who underwent CT guided FNAC of thoracic lesions between $11 / 06 / 2008$ and $1 / 12 / 2009$ was reviewed after seeking institutional consent. Pre procedure investigations and informed consent was obtained as per the institution protocol.

All patients underwent prior CECT of the chest to characterize the lung lesion. Patients with severe COPD who could not hold breath for a long time, patients having bleeding disorders and patients with contralateral pneumonectomy were excluded from the study. A fine spinal needle (23 gauge chibaneedle) was used for the FNAC. If the specimen sample obtained during the FNAC was inadequate for cytology, the procedure was repeated. If that provided a negative yield, the patient was referred for more invasive procedures such as tru cut biopsy and open biopsy thoracotomy.

Diagnostic accuracy was measured on basis of adequacy of sample for definite cytopathological diagnosis. Safety was measured in terms of complication rates. Feasibility in terms of the duration of post procedure hospital stay and total attempts required. We assumed age, sex and presence of emphysema as patient related variables. Size, depth of the lesion and location as the tumour related variables.

The procedure was conducted in the Radiology department at Shree Birendra Hospital. CT scan was performed to localize the lesion and skin entry point was marked with skin marker. Lidocaine (2\%) was used as local anesthesia and the same needle was left in place for reference as a single axial scan was obtained for tumour localization. A spinal needle (23 gauge Chiba needle) was used for the procedure. Needle tip position was confirmed with additional limited CT scans before the sample for cytology was obtained. A syringe $(10 \mathrm{ml})$ was attached to the needle's hub and the plunger pulled back to provide continuous suction. The needle point within the lesion was jiggled to free material from the lesion into the needle's lumen. Aspirates were obtained and smeared on slides, fixed in $95 \%$ alcohol before being sent to the pathology department for cytological evaluation along with relevant history and radiological findings.

A limited CT scan was performed immediately at the site of the FNAC to exclude pneumothorax and other FNAC related complications. The patients who developed pneumothorax, were kept under strict observation to monitor further deterioration. A repeat chest radiograph was performed next morning to assess progression of disease.

\section{RESULTS}

Thirty-nine cases were included in the study. Out of these, twenty four patients (61.54\%), were male and fifteen $(38.46 \%)$ were female in the age group $25-82$ years. Out of thirty-nine patients, twenty eight were smokers or had smoked in the past (71.79\%).

Diagnostic accuracy was calculated based on the final cytopathological report. There was adequate material in thirty four $(87.18 \%)$ cases while five cases $(12.82 \%)$ represented inadequate and non representative material (Two cases were hemorrhagic while three cases revealed only reactive cells).

Out of the thirty four patients where a final diagnosis was available, eight cases were reported as benign (23.53\%), twenty three samples were reported as definite malignant cases (67.65 \%) and three cases showed atypical cells $(8.82 \%)$, suggestive of malignancy. The spectrum of the final diagnosis of all the patients is given below in table 1.

Of the twenty three cases of confirmed malignacies, twelve were squamous cell carcinoma, three were small cell anaplastic carcinoma, three were metastatic lesions , two were adenocarcinoma, one was bronchioalveolar carcinoma, one was lymphoma and one was thymoma.

Out of the eight benign cases, four cases were reported as tuberculosis, two cases as benign adenoma and two cases as non tubercular infection. Six (17.65 \%) of the patients were under 40 yrs and none had malignancy in cytodiagnosis.

Pneumothorax was the commonest complication following the TTFNAC. Minimal pneumothorax was noted in four cases $(10.26 \%)$ but none required active management (placement of chest tube). Pain at the puncture site was observed with two patients $(5.13 \%)$ requiring oral NSAID and reassurance. Two patients $(5.13 \%)$ experienced minimal hemoptysis immediately following the procedure (both patients had also developed pneumothorax). A total of six patients who underwent CT guided FNAC developed complications (15.38\%) 
Table 1.Spectrum of final diagnosis( 39 cases)

\begin{tabular}{|c|l|}
\hline Cytopathologica diagnosis & $\begin{array}{l}\text { Number of } \\
\text { cases }\end{array}$ \\
\hline Malignant( $\boldsymbol{n}=\mathbf{2 6}$ ) & \\
\hline Squamous cell carcinoma & 12 \\
\hline Small cell anaplastic cancer & 3 \\
\hline Metastases & 3 \\
\hline Adenocarcinoma & 2 \\
\hline Bronchoalveolar carcinoma & 1 \\
\hline Lymphoma & 1 \\
\hline Thymoma & 1 \\
\hline Non specific malignancy & 3 \\
\hline Beningn ( $\boldsymbol{n}=\mathbf{8})$ & \\
\hline Benign adenoma & 2 \\
\hline Tuberculosis & 4 \\
\hline Non tubercular infection & 2 \\
\hline Inadequate sample $(\boldsymbol{n}=5)$ & \\
\hline Haemorrhagic tissue & 2 \\
\hline Only reactive tissue & 3 \\
\hline
\end{tabular}

Table 2.Summary of results of reported series.

\begin{tabular}{|l|l|l|l|l|}
\hline References & $\begin{array}{l}\text { No. of } \\
\text { Cases }\end{array}$ & $\begin{array}{l}\text { Diagnostic } \\
\text { Accuracy }\end{array}$ & $\begin{array}{l}\text { Pneum- } \\
\text { othorax }\end{array}$ & $\begin{array}{l}\text { Haemo- } \\
\text { rrhage }\end{array}$ \\
\hline Stanley et al $1987^{9}$ & 458 & $96.6 \%$ & $133(29 \%)$ & - \\
\hline $\begin{array}{l}\text { Vansonnenberg et al } \\
1988^{5}\end{array}$ & 150 & $82.7 \%$ & $64(42.7 \%)$ & 2 \\
\hline Haramati et al $1995^{10}$ & 32 & $81 \%$ & $3(9.4 \%)$ & - \\
\hline $\begin{array}{l}\text { Santambrogio et al } \\
1997^{4}\end{array}$ & 110 & $81 \%$ & $23(20.9 \%)$ & - \\
\hline $\begin{array}{l}\text { Gouliamos et al } 2000 \\
11\end{array}$ & 64 & $98.4 \%$ & $2(3.1 \%)$ & 1 \\
\hline $\begin{array}{l}\text { Mohammad et al } \\
2001^{12}\end{array}$ & 184 & $97 \%$ & $2(1.1 \%)$ & - \\
\hline Gupta et al $2002^{13}$ & 37 & $91 \%$ & $1(2.7 \%)$ & 1 \\
\hline Sing et al 2004 ${ }^{14}$ & 34 & $85.3 \%$ & $4(11.8 \%)$ & 4 \\
\hline Present study & 39 & $87.18 \%$ & & - \\
\hline
\end{tabular}

Fig 1.CT Procedure

a. Localization of needle tip within the lesion
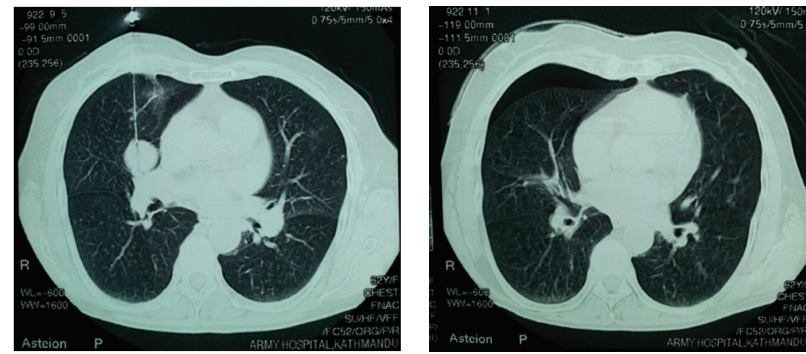

Figure 2. Malignant tumors

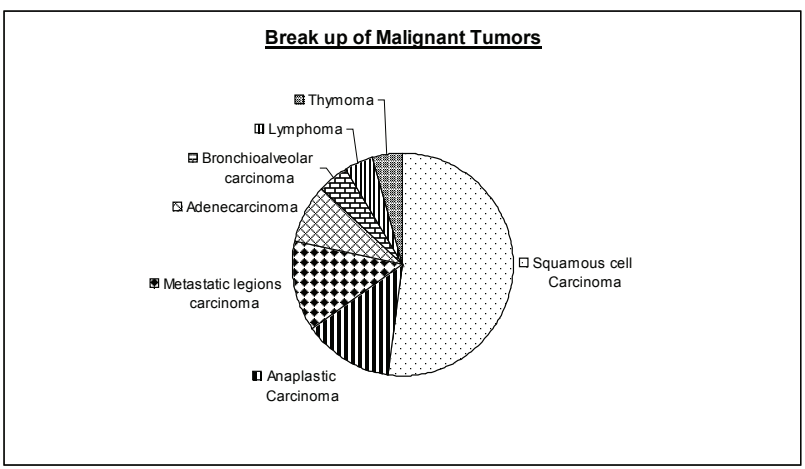

Figure 3. Benign cases

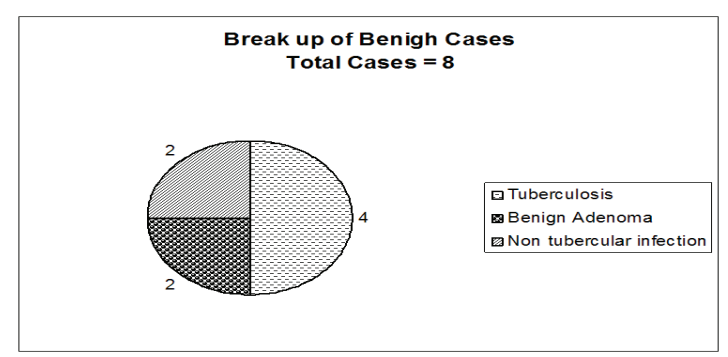

Figure 4. Complications



\section{圆Pneumothorax \\ 日 pain \\ pneumothorax with hemoptysis}

\section{DISCUSSION}

CT guided Percutaneous Transthoracic Fine Needle Lung Biopsy offers the opportunity to visualize the tip of the spinal needle within the lung lesion and perform immediate limited CT scan to prohibit immediate complication. FNAC performed under ultrasound guidance or fluoroscopy lack both these advantages.

Literature reports diagnostic accuracy (adequate yield for cytopathological diagnosis) ranging from $65 \%$ to $97 \%$ for CT guided percutaneous FNAC of lung nodules. A positive cytodiagnosis (diagnostic yield of FNAC) was made in $87.18 \%$ in our study. (3-10) 
Vansonnenberg et $a^{5} \mathrm{I}$ in 1988 performed Computed tomography (CT) was used to guide percutaneous fineneedle biopsy in 150 cases of difficult thoracic lesions. A diagnosis was made in 124 of 150 cases (82.7\%) (107 of 124 malignant and 17 of 26 benign lesions). Complications included pneumothorax (64 cases), hemoptysis (5 cases), hemothorax (2 cases), and pericarditis (1 case). As compared to this study our diagnostic yield was comparable with much less complications.

In a study done by Manhire et al ${ }^{6}$ in 2003 using trucut biopsy for lung lesions, a diagnostic yield (cytopathological diagnosis) of about $92 \%$ and high complication rate ( pneumothorax of about $62 \%$ ) was reported. The study demonstrates diagnostic yield of trucut biopsy sample at $90 \%$. The article reports a wide variation in reported diagnostic accuracies of FNAB between different institutions, ranging from $64 \%$ to $97 \%$.

In another study using trucut biopsy for lung lesions by Morgenrotet al ${ }^{7}$ in 1988 reported a diagnostic yield of $89 \%$ for accurate cytopathologicaldiagnosis.This study reported a complication rate of $15 \%$ and citied a complication rate of $10 \%$ to $60 \%$ from other studies. Şerife et al $^{8}$ in 2010 reports a cytopathological yield of trucut biopsy of lung lesions of more than $95 \%$ and a complication rate of more than $25 \%$.

We conclude that Transthoracic fine needle aspiration cytology (FNAC) of lung lesion using CT guidance is a relatively safe and accurate means of diagnosing benign and malignant lesions of the chest with negligible mortality and limited mortality. All the patients tolerated the procedure well. The most common complication following procedure was pneumothorax. Pneumothorax occurred in $4(10.26 \%)$ cases and haemoptysis in two cases $(5.13 \%)$ case. In all 4 cases, the pneumothorax was noted within 10 minutes of the procedure and it was mild in amount. 2 patient complaint of pain at site of puncture lasting 4-8 hours, however no medication was needed. These patients were kept under strict observation for any deterioration. A chest radiograph was done after 4 hours and it was observed that the amount of pneumothorax was mild to moderate $(<1 / 3$ rd of chest) in all the case. None of these patients required chest tube insertion. No evidence of intra-parenchymal haematoma was noted. The more serious complications such as pericardial tamponade, systemic air embolism and seeding of malignant cells in the needle tract were not encountered in our study.

The results of the diagnostic accuracy and complication of CT-guide aspiration cytology are comparable to other published studies Table 2.

\section{CONCLUSIONS}

Transthoracic Fine Needle Aspiration Cytology is a relatively safe, convenient, quick and economical procedure. We conclude that FNAC of lung lesion provides a high yield resulting in good diagnostic accuracy.

\section{REFERENCES}

1. Smith WG: Needle Biopsy of the Lung. With Special Reference to Diffuse Lung Disease and the Use of a New Needle. Thorax. 1964; 19:68-78.

2. Dahlgren S: A reply on needle biopsy of lung tumors. Lakartidningen.1966;63:3946-8.

3. Haaga JR, Alfidi RJ. Precise biopsy localization by computer tomography. Radiology. 1976; 118:603-7.

4. Santambrogio L, Nosotti M, Bellaviti N, Pavoni G, Radice F, Caputo V. CT-guided fine-needle aspiration cytology of solitary pulmonary nodules: a prospective, randomized study of immediate cytologic evaluation. Chest. 1997;112:423-5.

5. vanSonnenberg $E$, Casola $G$, Ho $M$, Neff CC, Varney RR, Wittich GR, Christensen R, Friedman PJ. Difficult thoracic lesions: CT-guided biopsy experience in 150 cases. Radiology. 1988;167:457-61.

6. Manhire A, Charig M, Clelland C, Gleeson F, Miller R, Moss H, Pointon K, Richardson C, Sawicka E. Guidelines for radiologically guided lung biopsy. Thorax 2003;58:920-36.

7. Morgenroth A, Pfeuffer HP, Austgen M, Viereck $\mathrm{HJ}$, Trendelenburg F. Six years' experience with perthoracic core needle biopsy in pulmonary lesions. Thorax. 1989;44:177-83.

8. Şerife SB, Şule A, Figen ÖE, Cüneyt A. Transthoracic lung and mediastinal biopsies obtained with the Tru-Cut technique: 10 years' experience. Turk J Med Sci. 2010;40:495-501.

9. Stanley JH, Fish GD, Andriole JG, Gobien RP, Betsill WL, Laden SA, Schabel SI. Lung lesions: cytologic diagnosis by fine-needle biopsy. Radiology. 1987;162:389-91. 
10. Haramati LB. CT-guided automated needle biopsy of the chest. Am journal of roentgenology. 1995;165:53-5.

11. Gouliamos AD, Giannopoulos DH, Panagi GM, Fletoridis NK, Deligeorgi-Politi HA, Vlahos LJ. Computed tomography-guided fine needle aspiration of peripheral lung opacities. An initial diagnostic procedure. Acta cytologica. 2000;44:344-8.

12. Mostafa MG: Computed tomography guided fine needle aspiration cytology in the diagnosis of thoracic lesions, Journal of the Indian Medical Association 2001, 99:550-551, 553
13. Gupta S, Wallace MJ, Morello FA, Jr., Ahrar K, Hicks ME: CT-guided percutaneous needle biopsy of intrathoracic lesions by using the transsternal approach: experience in 37 patients, Radiology 2002, 222:57-62

14. Singh JPG, L. ; Setia, V.: Computed tomography (Ct) guided transthoracic needle aspiration cytology in difficult thoracic mass lesions-not approachable by USG, Indian J Radiol Imaging 2004, 14395-400: 